\title{
Hidrelétricas no início do século XX: tratadística e periódicos
}

\author{
DOSSIER ELETROMEMÓRIA: PAISAGEM E HISTÓRIA
}

\section{Denise Fernandes Geribello}

\section{Resumo}

As primeiras usinas hidrelétricas brasileiras surgiram em finais do século XIX respondendo a demandas impostas pelo setor industrial, então em processo de consolidação, e promovendo o aprimoramento da vida urbana por meio da iluminação pública e dos sistemas de transporte elétricos. Naquele momento, o projeto e a construção de tais empreendimentos constituía um grande campo de experimentação. Muitas foram as inovações técnicas e construtivas necessárias para adaptar esta nova tipologia ao solo nacional. Apesar das peculiaridades impostas pelo caso brasileiro, os exemplares nacionais compartilham com usinas ao redor de todo o mundo uma série de princípios construtivos e arquitetônicos. Tal semelhança decorre, dentre outros fatores, da disseminação de uma base teórica comum por meio de tratados de construção de usinas hidrelétricas, da tratadística relativa à construção civil e dos periódicos especializados em engenharia e construção. Buscando explorar estas fontes e compreender seu papel na concepção das usinas hidrelétricas brasileiras, este artigo trata do uso destes materiais no projeto da Usina de Itatinga, Bertioga [SP].

\section{Palavras-chave}

Usina de Itatinga, patrimônio industrial, patrimônio cultural, usinas hidrelétricas.

\section{Hidropower plants at the begining of $\mathrm{XX}^{\text {th }}$ century: treatises and journals}

\begin{abstract}
The first Brazilian hydropower plants were built in the end of the 19th century to fulfill the demands of the emerging industrial sector and to improve urban life through public lightening and transportation systems. By then, the plants' design and construction was a field of experimentation. Many were the technical and constructive innovations needed to adapt this new typology to Brazilian ground. In spite of the national peculiarities, the hydropower plants all over the world share a great deal of constructive and architectonical principles. This resemblance is originated, among other factors, by the dissemination of a common theoretical basis through hydropower plants construction's treatises, treatises related to civil construction, and engineering journals. In order to explore those sources and to comprehend their role in the conception of Brazilian hydropower plants, this article debates their use in the design of Itatinga Hydropower plant, which is located in Bertioga City, São Paulo.
\end{abstract}

\section{Keywords}

Itatinga hydropower plant, industrial heritage, cultural heritage, hydropower plants. 


\section{Introdução}

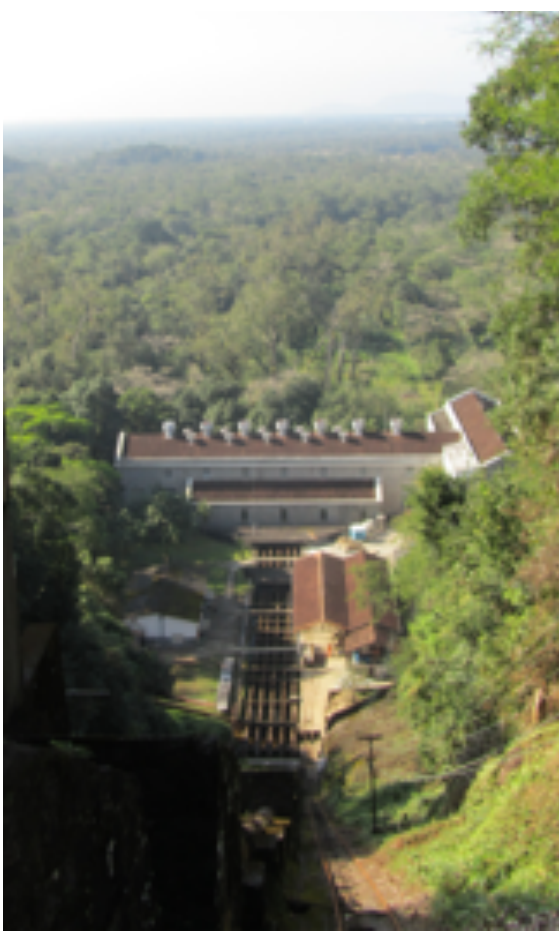

Figura 1. Usina de Itatinga. Foto: Denise Geribello, 2013.
As primeiras usinas hidrelétricas brasileiras surgiram em finais do século XIX respondendo a demandas impostas pelo setor industrial, então em processo de consolidação, e promovendo o aprimoramento da vida urbana por meio da iluminação pública e dos sistemas de transporte elétricos. Naquele momento, o projeto e a construção de tais empreendimentos constituía um grande campo de experimentação. Muitas foram as inovações técnicas e construtivas necessárias para adaptar esta nova tipologia ao solo nacional. Apesar das peculiaridades impostas pelo caso brasileiro, os exemplares nacionais compartilham com usinas ao redor de todo o mundo uma série de princípios construtivos e arquitetônicos. Tal semelhança decorre, dentre outros fatores, da disseminação de uma base teórica comum por meio de tratados de construção de usinas hidrelétricas, da tratadística relativa à construção civil e dos periódicos especializados em engenharia e construção. Buscando explorar estas fontes e compreender seu papel na concepção das usinas hidrelétricas brasileiras, este artigo trata do uso destes materiais no projeto da Usina de Itatinga ${ }^{1}$, uma pequena central hidrelétrica ( $\mathrm{PCH})$ a fio d'água centenária, situada em meio à Mata Atlântica, que atravessa os municípios de Bertioga, Guarujá e Santos, Estado de São Paulo, Brasil. Ainda hoje suas turbinas são movidas pelas águas do Rio Itatinga e geram cerca de $80 \%$ da demanda energética do Porto de Santos, um dos mais movimentados portos da América Latina.

Este artigo se inicia pela análise do arranjo geral da Usina de Itatinga e, posteriormente, discorre sobre sua casa de força, sempre confrontando aspectos arquitetônicos, construtivos e relativos à organização espacial da usina com o conteúdo apresentado pela bibliografia. Finalmente, o texto trata da presença de Itatinga em revistas especializadas.

Uma ressalva se faz necessária antes da análise do caso proposto. Importante mencionar que os objetos aqui tratados não constituem as únicas formas de circulação dos saberes em questão. Eles foram selecionados em decorrência de seu papel fundamental no caso da Usina de Itatinga. Outros fatores, como, por exemplo, a produção de manuais técnicos por fabricantes, a polarização de escolas de engenharia e o trânsito de profissionais brasileiros no exterior, bem como de profissionais estrangeiros no Brasil, também são fundamentais e não devem ser desconsiderados.

\section{A Usina de Itatinga}

A construção da Usina de Itatinga está diretamente ligada à concessão de direitos para exploração e melhoramentos do Porto de Santos a um grupo de empresários que viria a ser denominado Companhia Docas de Santos (CDS) ${ }^{2}$. Em meio à gestão das atividades portuárias, a CDS obtém a concessão para a construção de uma usina hidrelétrica em $1901^{3}$. Dessa forma, a própria companhia poderia gerar a energia a ser utilizada na iluminação do porto e no maquinário de suas oficinas e do cais.

\footnotetext{
${ }^{1}$ As análises apresentadas neste artigo integram a pesquisa de doutorado "A patrimonialização de estruturas industriais: o caso da Usina de Itatinga”, em desenvolvimento no programa de Pós-Graduação da FAU-USP, sob orientação da Profa. Dra. Beatriz M. Khül, com bolsa CAPES.

${ }^{2}$ O grupo liderado por Cândido Gaffrée e Eduardo Guinle, inicialmente, é transformado na empresa Gaffrée, Guinle \& Cia. Mais tarde, se torna Empresa de Melhoramentos do Porto de Santos e, em seguida, Companhia Docas de Santos (Maziviero, 2008, p.58).

${ }^{3}$ Decreto ${ }^{\circ} 4.088$, de 22 de Julho de 1901.
} 
Após a obtenção das devidas concessões de aproveitamento de recursos hídricos e a realização de estudos pelo Engenheiro Guilherme Benjamin Weinschenck ${ }^{4}$, que estava à frente das obras de modernização então em curso no porto, foi estabelecida, em linhas gerais, a localização da represa, o traçado do canal, a posição da câmara d'água, o desenho da linha de tubos e o local da casa de força, bem como a configuração da linha de postes conectando a casa de força ao Porto de Santos (WEINSCHENCK, 1903-1904). O projeto da usina foi aprovado pelo governo federal em $1906^{5}$. A aprovação, entretanto, não significou sua conclusão, muito pelo contrário. Ao longo de um extenso período de tempo, este grande projeto foi sendo elaborado, reelaborado e seguiu em desenvolvimento mesmo após o início das obras, em 1908 (BERENGER, 1954, p.29).

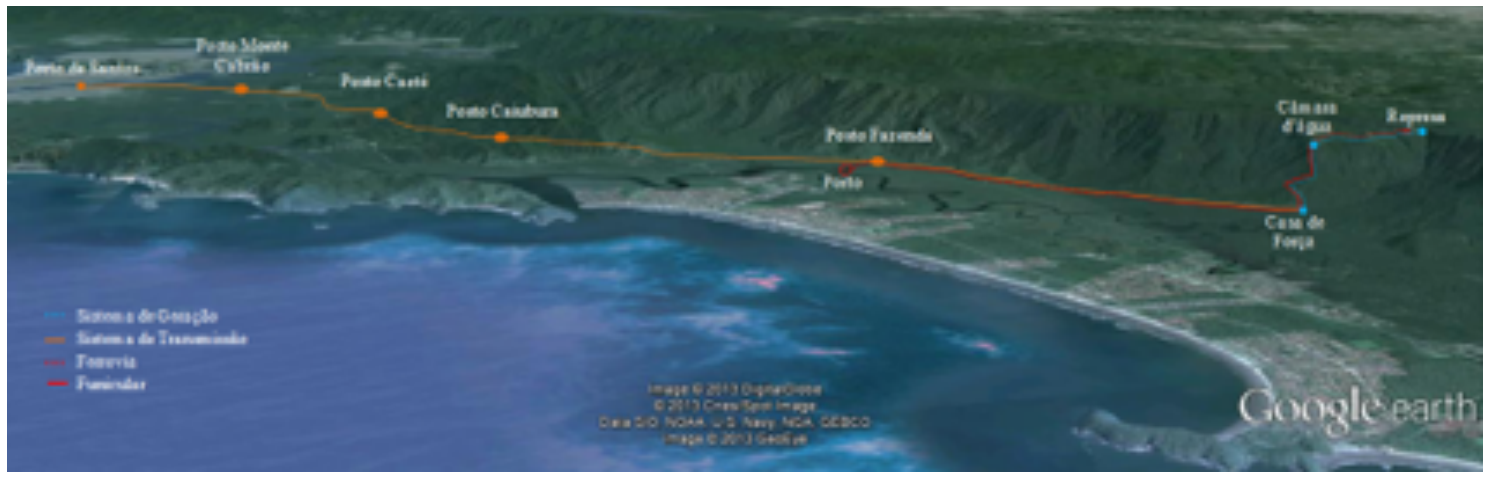

Figura 2. Arranjo geral da Usina de Itatinga. Fonte: Imagem elaborada a partir de foto de satélite disponível no programa Google Earth. Acesso em 03 mar. 2014.

Em um caderno de estudo de Weinschenck, são analisadas três hidrelétricas da estadunidense Bay Counties Power Company (WEINSCHENCK, 1903-1904, p.40-42). As Usinas de Colgate, Nevada e Brown's Valley funcionam em paralelo e geram energia a partir das águas do Rio Yuba, localizado na cadeia montanhosa Sierra Madre, Estado da Califórnia. Estas usinas figuram como empreendimentos exemplares em diversos tratados referentes à construção de hidrelétricas da época, dentre estes tratados estão: Electric transmission of water power (ADAMS, 1906), The alternating current transformer (Baum, 1903), Electric power transmission; a practical treatise for practical men (BELL, 1901), Henley's encyclopædia of practical engineering and allied trades (HORNER, 1906) e Long-distance electric power (HUTCHINSON, 1907).

Colgate é o estabelecimento que recebe maior destaque tanto nestas publicações como nas anotações do engenheiro. Conforme descrito em Hutchinson (1907, p.334-335), Colgate possui uma barragem localizada quase 13 quilômetros acima da casa de força. Da barragem, parte um grande canal de madeira com seção de 1,75 por 2,15 metros, que conduz a água até a linha de tubos, que, por sua vez, vence um desnível de 214 metros. Cinco tubos de ferro fundido e aço, ancorados em maciços de concreto, conduzem o fluxo acompanhando a encosta da montanha até um grande tubo que distribui a água para as rodas d'água. A solução adotada em Itatinga segue a mesma lógica da adotada em Colgate.

A Usina de Itatinga se localiza na escarpa da Serra do Mar. Assim como Colgate, se implanta em uma encosta íngreme. Em uma garganta do Rio Itatinga, no alto desta escarpa, se situa sua pequena represa, de onde parte um canal que se estende acompanhando a encosta. 0 canal possui seção retangular, medindo 1,5 metro de largura por 2,4 metros de altura, dimensões próximas ao canal

\footnotetext{
${ }^{4}$ Weinschenck nasceu em 1847, em Areal, Rio de Janeiro. Concluiu os estudos básicos em Breslau (na época Prussia, hoje Polônia) e cursou Engenharia Civil e Mecânica em Chemnitz, Alemanha, tendo concluído os estudos em 1870 (Rocha, 1948, p.6). Acredita-se que Weinschenk tenha estudado na Technische Universität Chemnitz, então chamada Königliche Höhere Gewerbschule. Na segunda metade do século XIX, a escola contava com cursos técnicos em Mecânica, Química e Agronomia (Mechanische Technik, Chemische Technik e Landwirtschaft), sendo a engenharia civil parte integrante do currículo destes três cursos , Conforme consta no texto "Geschichte der TU Chemnitz", disponível na página da própria universidade <https://www.tu-chemnitz.de/tu/geschichte/zeittafel.php>. Acesso em 03 mar. 2014.

${ }^{5}$ Decreto ${ }^{\circ}$ 6.139, de 11 de Setembro de 1906.
} 
da usina americana. Porém, enquanto o canal de Itatinga foi construído em pedra, o de Colgate foi feito em madeira. Ao longo deste canal há túneis que atravessam rochas da encosta. 0 canal termina na câmara d'água, de onde partem cinco tubos que se estendem ao longo do divisor de águas, mesmo número de tubos utilizados na usina americana. Esta linha de tubos conduz a água à casa de força, onde a energia potencial é transformada em eletricidade. Em ambos os casos, a casa de força é construída em pedras nativas, com grandes aberturas em arco pleno e tesouras metálicas 6 . Ao adentrar a casa de força de Itatinga, a linha de tubos atravessa um conjunto de válvulas de distribuição que integra um sistema de alimentação cruzada, sistema este também utilizado em Colgate. Este sistema permite que qualquer um dos tubos alimente qualquer uma das turbinas. Ao sair da casa de força, a água segue por meio de um canal aberto até retomar o leito do Rio Itatinga. Da casa de força partem as linhas de transmissão, que se estendem ao longo da planície, levando a eletricidade ao Porto de Santos. Tanto no caso estadunidense como no brasileiro, as linhas de transmissão são extensas e atravessam recursos hídricos navegáveis, demandado grandes vãos livres. Nos dois casos, as usinas foram construídas em resposta a demandas industriais. Enquanto o foco da companhia americana era o fornecimento de energia para atividades de mineração, Itatinga tinha como objetivo o abastecimento do porto.
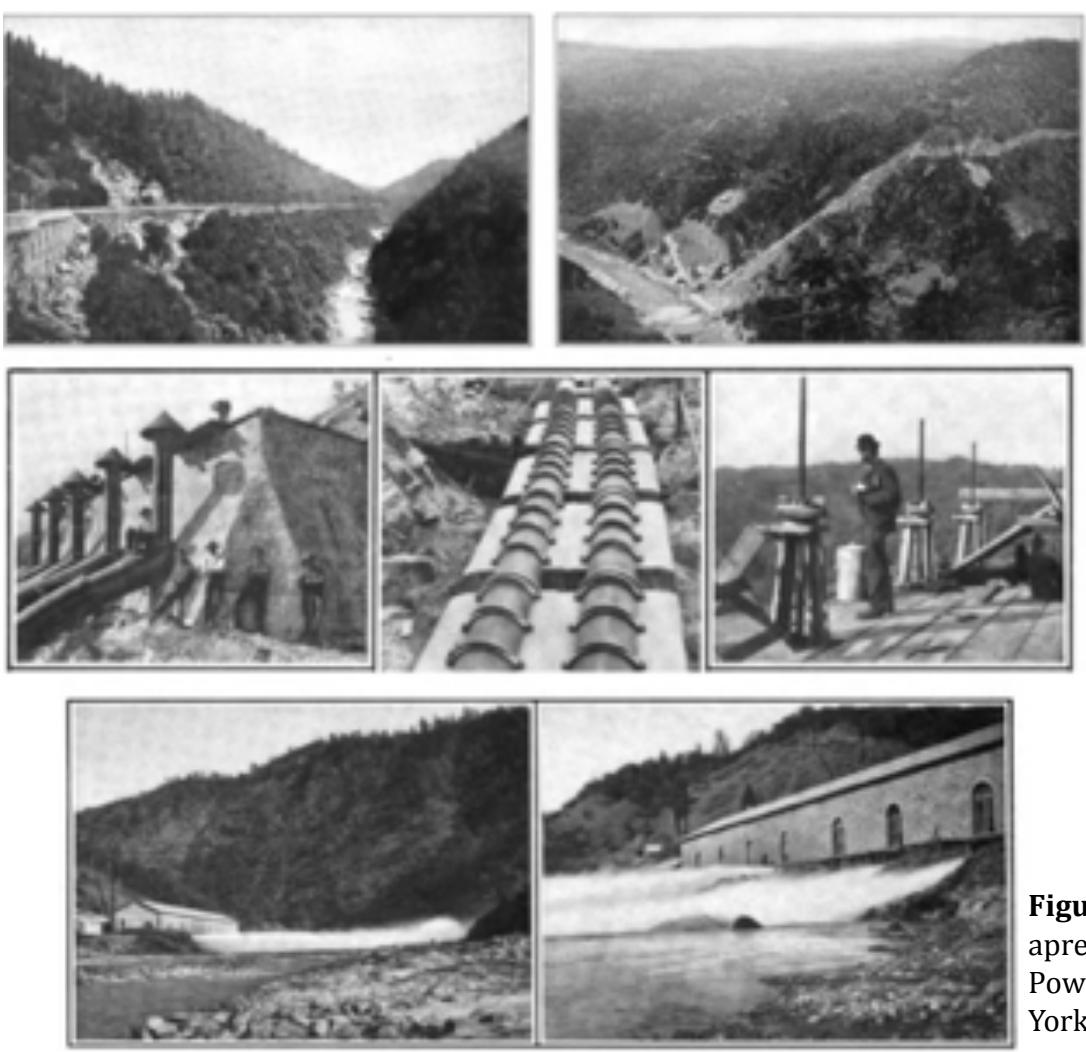

Figura 3. Imagens de Usina de Colgate apresentadas em PERRINE, F. A. C. Powerplants of the Pacific Coast. New York: New York Electrical Society, 1902.

\section{A Casa de Força}

Assim como o arranjo geral da usina, a configuração da casa de força de Itatinga dialoga com princípios ditados pela tratadística relativa à construção de hidrelétricas do início do século XX. Conforme apontado por Hutchinson, a maior parte das casas de força apresentam plantas quadradas ou retangulares, com sua maior dimensão sendo a longitudinal (1907, p. 311). A água é, predominantemente, conduzida latitudinalmente através do edifício e as turbinas são instaladas com o eixo paralelo às paredes longitudinais (1907, p. 312). A localização dos transformadores diverge, sendo uma das variações a instalação destes equipamentos em um compartimento separado do restante da estrutura. A instalação dos quadros em uma galeria sobre o pavimento principal é um arranjo recorrente (1907, p. 313). Em Itatinga, Weinschenck trabalha dentro destes

\footnotetext{
${ }^{6}$ Interessante notar que, enquanto a casa de força de Itatinga se mantém com poucas modificações, a de Colgate foi reconstruída em 1948 e, novamente, no final da década de 1960 (Ross, 1999).
} 
preceitos, mas desenvolve uma solução inovadora. 0 engenheiro adota a planta retangular, mas cria dois setores. Um deles abriga turbinas e geradores. A linha de tubos chega perpendicularmente à maior dimensão do edifício, como sugerem os tratados, entretanto, a tubulação que deixa as turbinas segue longitudinalmente. 0 outro setor abriga, no primeiro pavimento, os transformadores, separados das turbinas e geradores como recomendado e, no segundo pavimento, os quadros de controle, seguindo também a tratadística. Estes dois setores são organizados em "T", partido não observado em nenhum dos tratados ou dos projetos analisados em periódicos especializados, que responde com primazia às demandas específicas dos equipamentos e da dinâmica de funcionamento da usina.

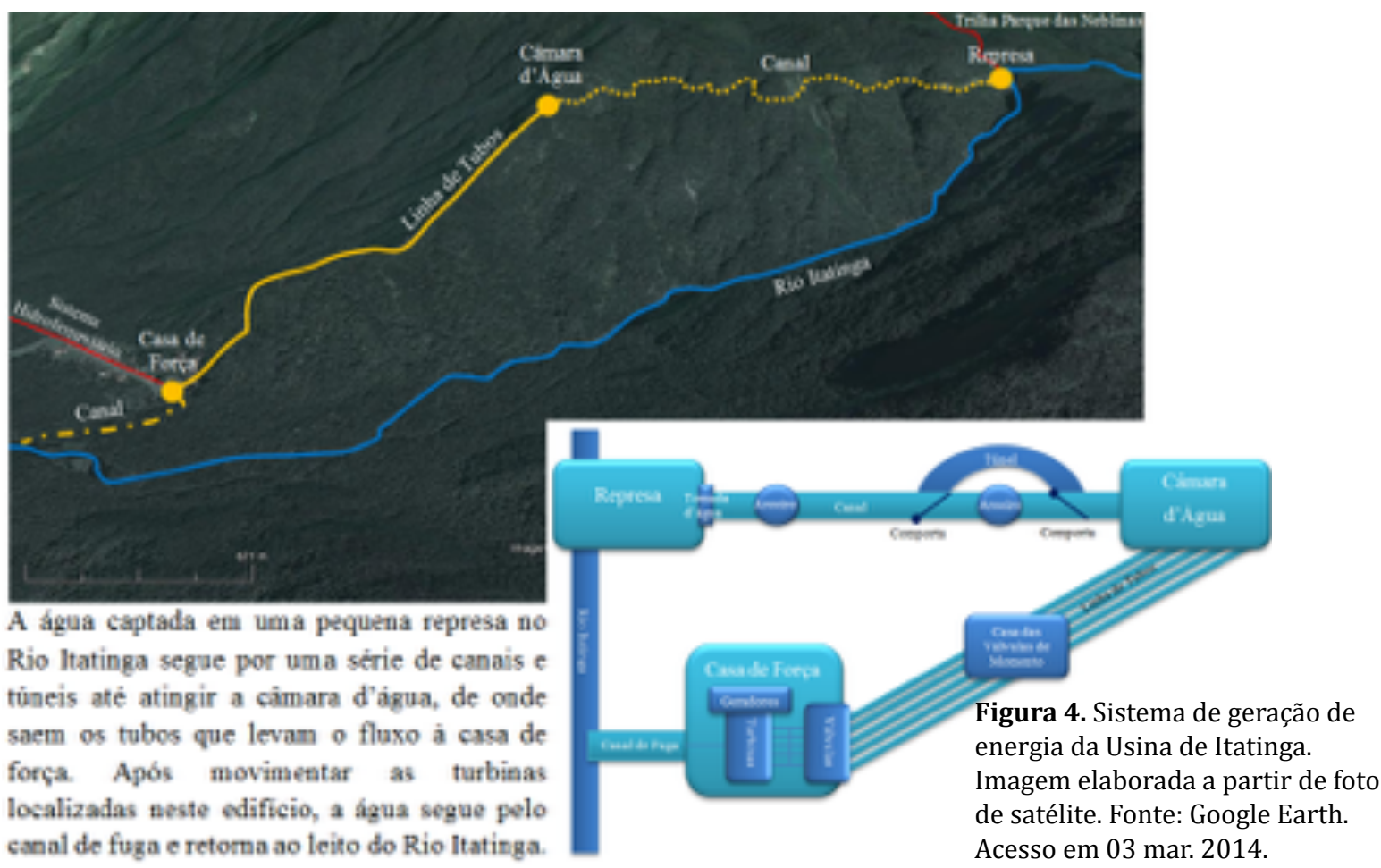

Assim como sua organização espacial, aspectos construtivos da casa de força também dialogam com os tratados referentes à construção de hidrelétricas produzidos no início do século XX (Figura 5). Conforme apresentado nesta literatura, a cobertura destes edifícios é geralmente composta por treliças metálicas com arranjos diversos, predominando as treliças em arco (HUTCHINSON, 1907, p. 312). A cobertura de Itatinga é estruturada por treliças metálicas, porém do tipo belga e não em arco. O projeto e as peças deste sistema treliçado foram produzidos em 1906, em Hamburgo, pela H.C.E. Eggers \& $\mathrm{Co}^{7}$.

As telhas francesas presentes em Itatinga (Figura 6), produzidas pela Roux-Freres, em sua filial de Saint Henri-Marseille, sul da França, se incluem nos "numerosos revestimentos de cobertura patenteados" então utilizados nas casas de força (HUTCHINSON,1907, p. 312).

A alvenaria de pedra é apontada como uma das técnicas mais recorrentes na construção de casas de força e em suas fundações (HUTCHINSON, 1907, p. 311), o estudo de caso não foge a esta regra. Inclusive, no caso de Itatinga, a construção das fundações em alvenaria foi a fase mais desafiadora da construção da casa de força, conforme atesta o próprio engenheiro em artigo publicado na Revista Polytechnica em 1909 - um dos diversos artigos publicados a respeito da usina em periódicos especializados, tratados a frente. 0 terreno de "mangue não consolidado" demandou a [...]

[...] creação de base artificial resistente por meio de pilares de alvenaria que são enterrados até encontrar terreno firme e resistente e que sustentam chapas de concreto armado, sobre as quaes se construe o edifício (WEINSCHENCK, 1909, p. 257).

\footnotetext{
${ }^{7}$ Esta indústria teria sido contratada pela CDS por meio da Companhia Johannes Schuback \& Söhne, de Hamburg, conforme consta em pranchas do projeto.
} 


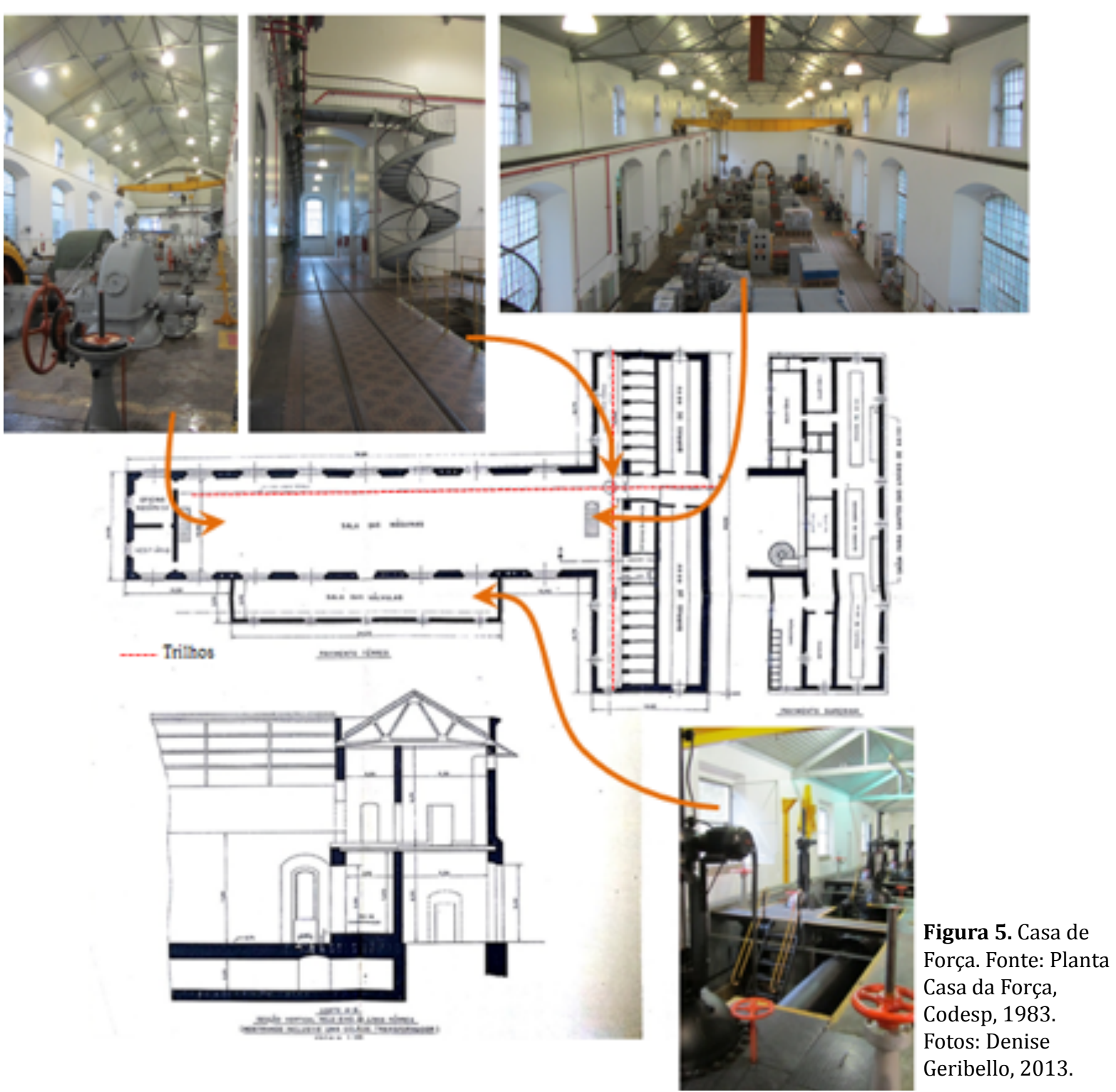

Os pilares cilíndricos, cujo diâmetro externo varia de 1,80 a 2,50m e o interno de 1,20 a 1,56m, foram construídos em alvenaria de pedra com argamassa de cimento. Cada um destes pilares era erigido sobre uma base cilíndrica de ferro fundido, com a face inferior em gume para facilitar a penetração no solo. Conforme o pilar adentrava no terreno, procedia-se com a escavação em seu poço interior (WEINSCHENCK, 1909, p. 257). Após encontrar terreno resistente, o que acontecia a uma profundidade média de 12 metros, os poços eram preenchidos de concreto e respaldados na altura da base das chapas de concreto armado que viriam a suportar (WEINSCHENCK, 1909, p. 258).
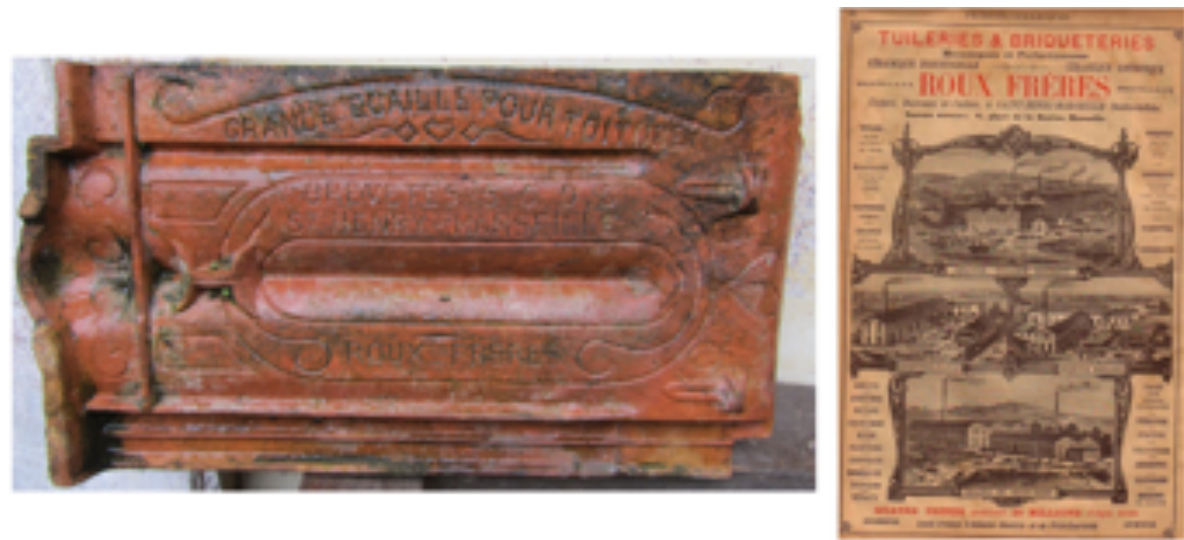

Figura 6. Telha francesa usada em Itatinga. Foto: Denise Geribello, 2013. Encarte publicitário da Companhia Roux Fréres, Annuaire Almanach de Commerce \& Industrie Didot-bottin, 1894. 
O Encarte publicitário da Companhia Roux Fréres, Annuaire Almanach de Commerce \& Industrie Didot-bottin, 1894 pode ser acessado via Internet ${ }^{8}$.

As paredes da casa de força foram construídas em alvenaria autoportante de pedras com argamassa de areia e cimento. 0 paramento exterior é composto por pedras irregulares de maiores dimensões, mais rijas e de melhor aspecto, aparelhadas apenas nas faces expostas a fim de remover as asperezas e maiores irregularidades. 0 interior das paredes é constituído por pedras menores e irregulares. 0 travamento desta alvenaria é garantido pelo uso de pedras de cauda comprida, de aparelho mais cuidadoso, junto aos cunhais, que são assentes em alhetas. Nas vergas, tanto retas quanto em arco abatido, as aduelas e chaves são constituídas por pedras de cantaria. Os pés direitos das aberturas são feitos em pedras aparelhadas com mais cuidado em relação às utilizadas no restante do paramento, entretanto, não se trata de pedras em cantaria. 0 paramento interno é rebocado e, em sua maior parte, pintado, com algumas regiões revestidas por azulejos a meia altura.

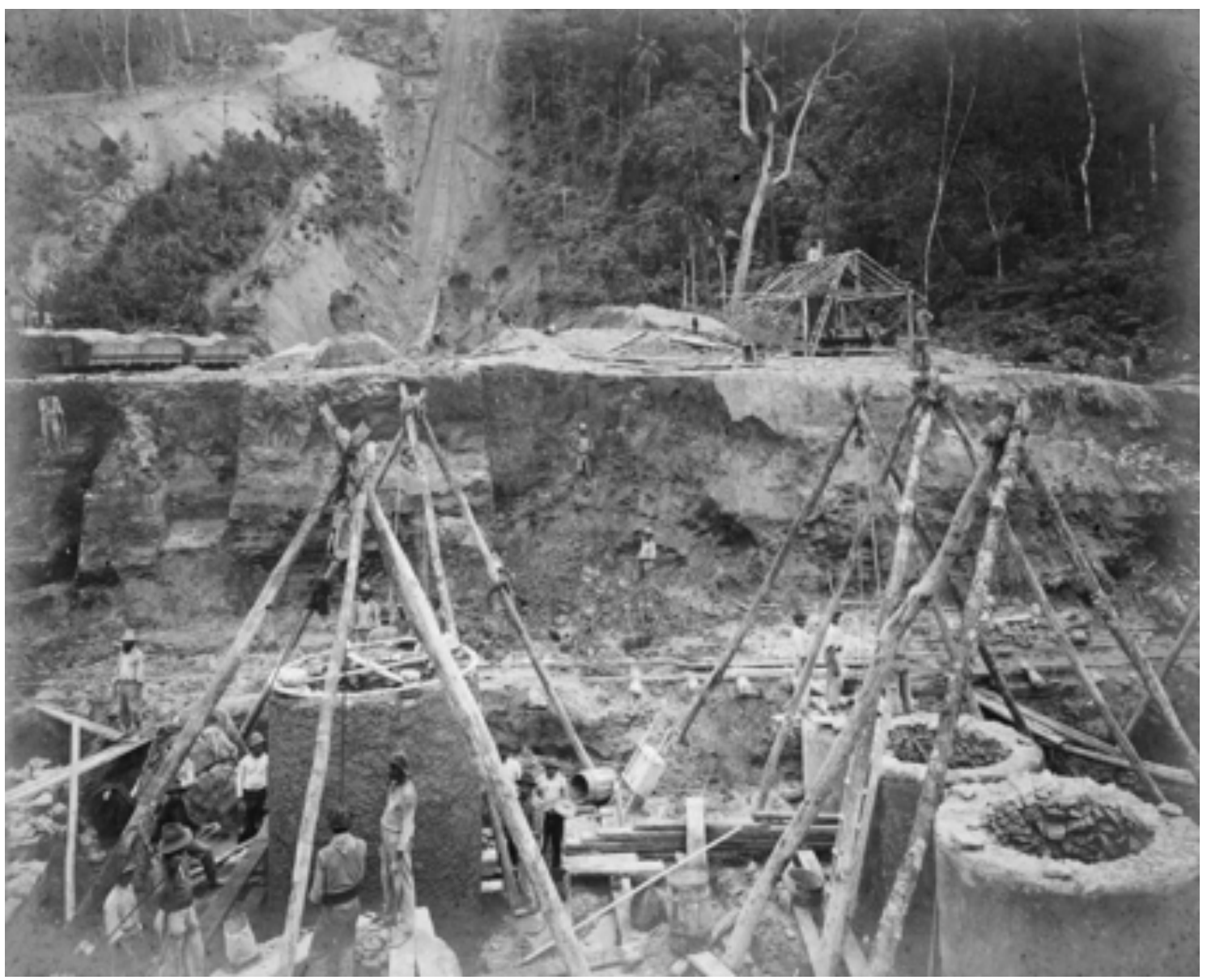

Figura 7. Acervo Docas S/A, s.d.

0 aparelho de alvenaria empregado nesta edificação se insere na categoria que Reynaud descreve como constructions mixte (construção mista) em seu Traite d'architecture (1875, p. 173). Caracterizado pela mistura de pedras de cantaria, pedras pequenas, tijolos e concreto (Figura 9), este sistema construtivo era, segundo ele, o mais usual. Este sistema está presente em ruínas da antiguidade, correspondendo ao aparelho romano opus incertum — conforme Reynaud, consiste em [...]

[...] une maçonnerie de blocailles ou de béton contenue à l'extérieur par de petits moellons bruts mis en parement de chaque côté du mur. Les angles étaient consolides au moyen de chaînes formées par des assises horizontales de pierre de taille, de fort moellons équarris ou même de brique (1875, p. 174).

\footnotetext{
${ }^{8}$ Disponível em <http://4.bp.blogspot.com/_WbbcTdk89xo/S0NGdUw9nMI/AAAAAAAAA88/mB9sVcbdjoo/s1600-h/ publicit\%C3\%A9+Roux+fr\%C3\%A8res+(Didot-bottin+1894).jpg> Acesso em 28 mar 2014.
} 


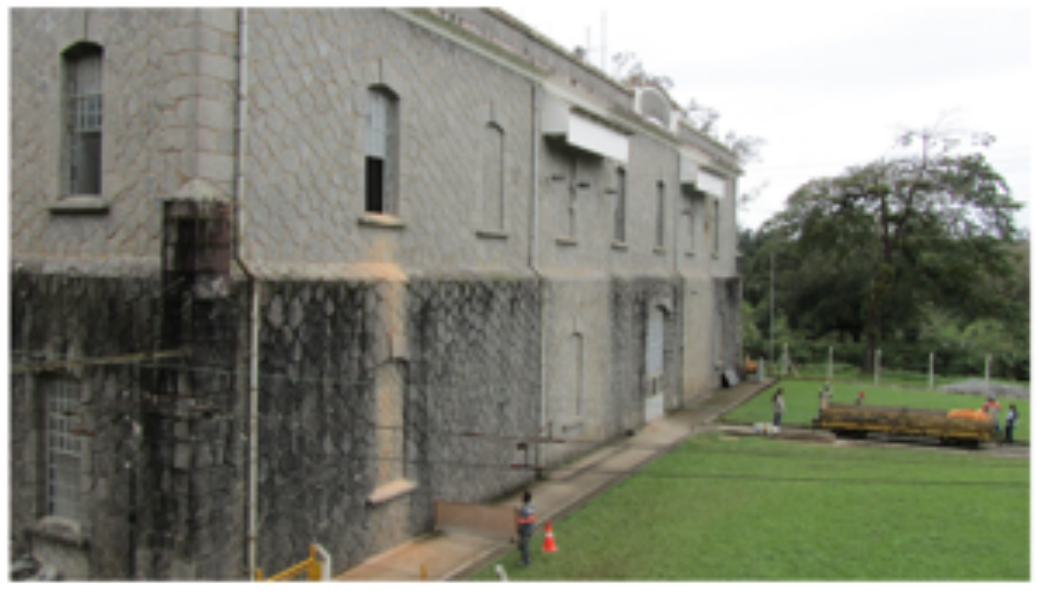

Figura 8. Casa de Força, Usina Itatinga. Foto: Denise Geribello, 2013.
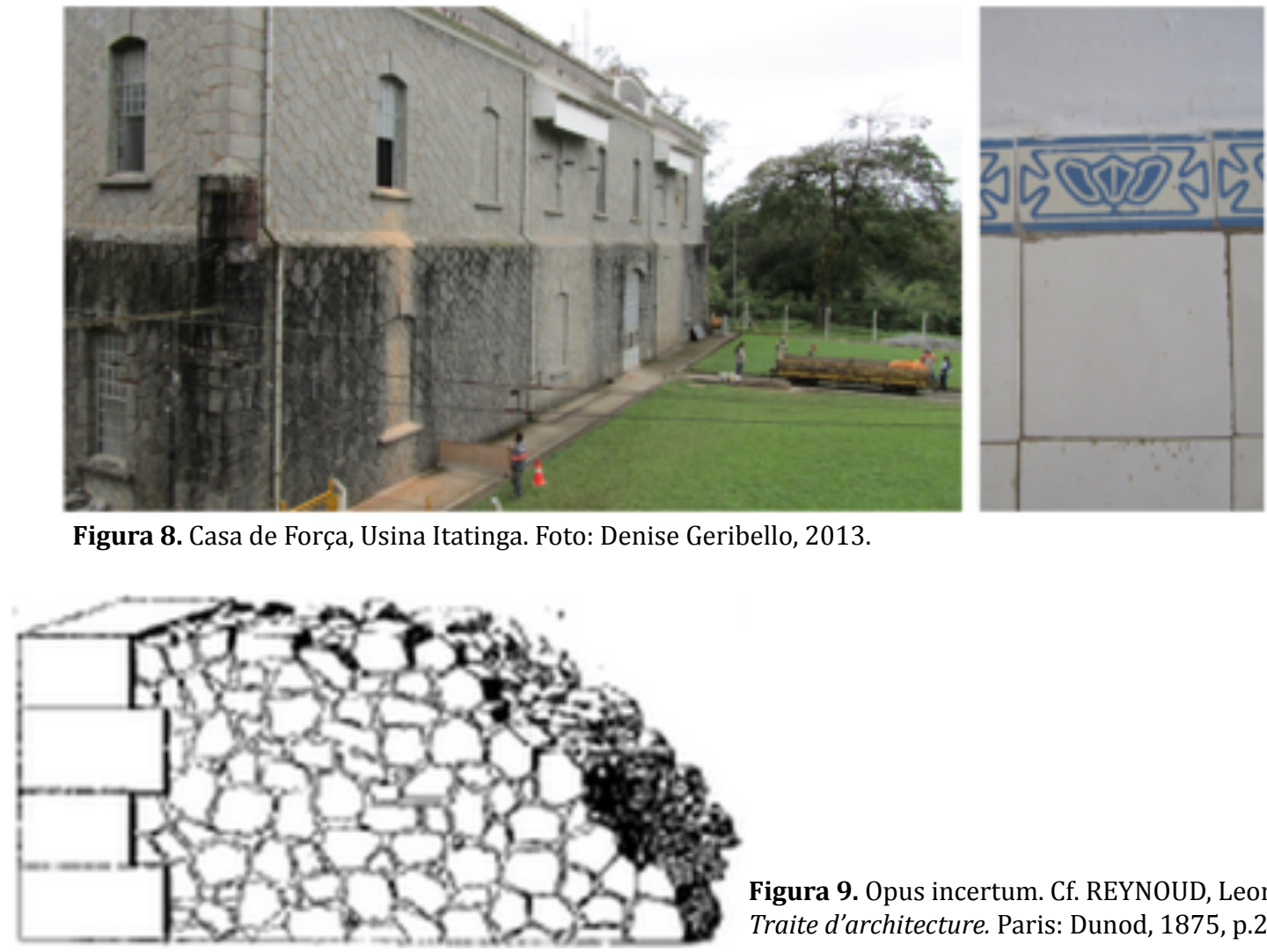

Figura 9. Opus incertum. Cf. REYNOUD, Leonce. Traite d'architecture. Paris: Dunod, 1875, p.2.

Este aparelho de alvenaria é descrito em muitos outros tratados do período, como, por exemplo, Segurado (s.d.) e Cloquet (1898-1901). Da mesma forma, as abobadilhas utilizadas no pavimento superior da casa de força configuravam uma técnica recorrente no período e muito difundida pelos tratados da época. Trata-se de pequenas abóbadas de berço construídas entre vigas de ferro em perfil I, apoiadas em muros da edificação. Conforme descrito por Segurado em Alvenaria e Cantaria as abobadilhas são:

abóbadas circulares de pequena flecha ou mesmo chatas, construídas entre vigamentos de ferro pouco afastados entre si, a fim de formarem pavimentos incombustíveis; pode-se empregar tijolo de burro ${ }^{9}$ ou betom. São hoje muito usadas nas construções vulgares, em armazéns, fábricas, etc. (s.d., p.163).

A casa de força é coroada por platibanda arrematada por uma singela cimalha (Figura 11). A platibanda, sobre a qual há uma cornija, é interrompida por um pequeno frontão em arco abatido que marca a única entrada do edifício. A fachada principal, composta por quatro janelas e uma porta, é assimétrica. 0 eixo estabelecido pelo vão de entrada, sobre o qual se localiza o já mencionado frontão, divide a fachada horizontalmente na proporção 3:2. A fenestração, entretanto, não segue esta razão. A localização das janelas resulta da configuração interna do edifício e do posicionamento de equipamentos. Mesmo não havendo simetria na fenestração, há molduras e vergas semelhantes às dos vãos adoçadas à parede com a finalidade de conferir certo ritmo à fachada ${ }^{10}$.

O equilíbrio preciso entre a funcionalidade e a dimensão estética da casa de força também reflete a lógica predominante no período. Em seu tratado sobre hidrelétricas, Koester aborda este equilíbrio como um acordo harmonioso entre arquiteto e engenheiro. Conforme argumenta o autor, [...]

\footnotetext{
${ }^{9}$ No período, os tijolos maciços eram vulgarmente chamados de "tijolo de burro".

${ }^{10}$ Importante mencionar que as molduras em questão estão presentes no projeto da usina. Não se trata, portanto, de antigos vãos que foram emparedados.
} 
[...] necessity requires only a building of sufficient support, to shelter and protect the machinery and those who operate it, and must be of durable construction. An ornamental building will not increase the efficiency of the machinery; it increases the fixed charges. But, at the same time, it is required from an aesthetic point of view, and will, no doubt, have certain effect upon the moral of the operating force, whose efficiency will be increased thereby (1909, p.107).

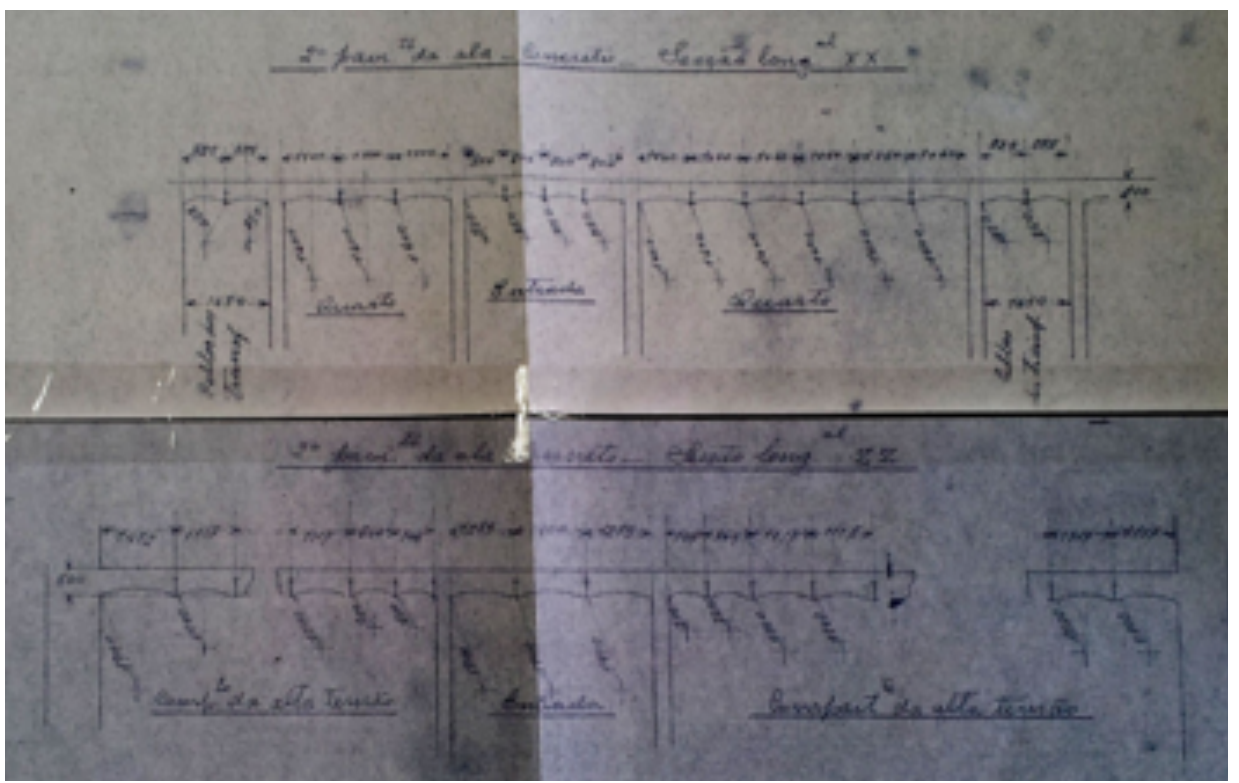

Figura 10. Sistema de abobadilhas entre vigas de ferro do pavimento superior. Parte da planta da Casa de Força, 1912 (cópia).

A simplicidade no desenho, a harmonia com o entorno e a ornamentação moderada constituíam elementos de primeira importância no projeto de uma casa de força. A edificação construída em Itatinga responde com qualidade a estes três requisitos.

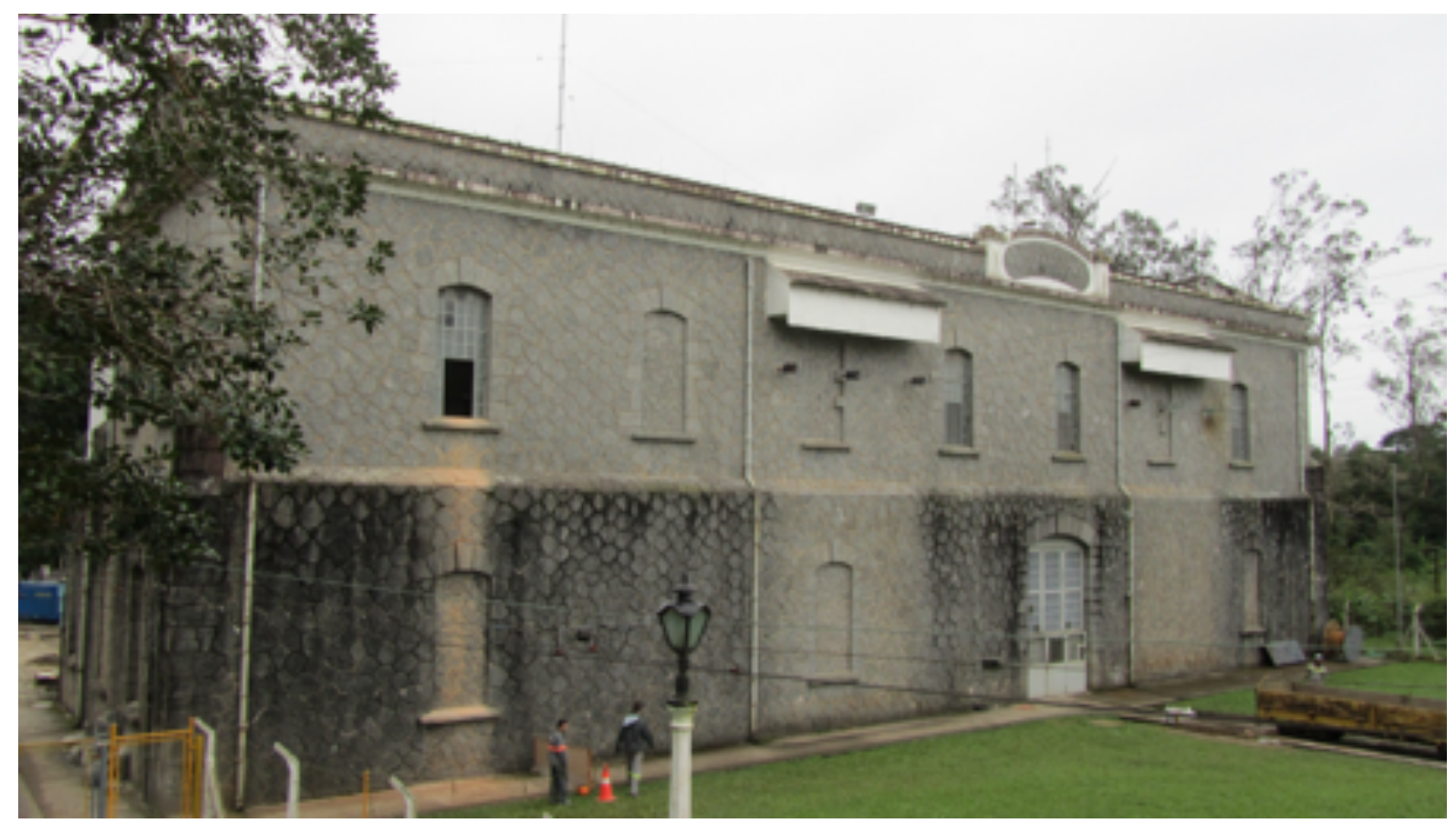

Figura 11. Fachada da Casa de Força, Usina Itatinga. Foto: Denise Geribello, 2013. 


\section{A Usina de Itatinga: uma referência}

A breve análise tecida até o momento dá pistas de como a Usina de Itatinga se apropria do conhecimento em circulação no período. Não se trata, entretanto, de uma simples importação de modelos estrangeiros. Em alguns momentos as soluções adotadas no caso de estudo são marcadas pelo alinhamento como os preceitos difundidos nos manuais, em outros, pela inovação. Os conhecimentos apropriados e gerados na construção de Itatinga, por sua vez, se difundem em diversas publicações. Artigos sobre a usina figuram em publicações tanto nacionais, quanto originárias dos Estados Unidos, Canadá, Inglaterra, França, Alemanha e Áustria ${ }^{11}$, em sua maioria datando de 1912, dois anos após sua inauguração.

Se, por um lado, os artigos tratam da qualidade projetual de Itatinga, por outro, mencionam as dificuldades encerradas em sua construção. Em 1912, a recém-inaugurada Usina de Itatinga, "a perfect modern system" (1912, p.584), foi objeto de um artigo publicado na revista Electrical World. Ao tratar da construção do canal que liga a represa à câmara d'água, o autor coloca que [...]

[...] numerous accidents occurred during the construction of the flume. One landslide alone buried 12 men. If one will consider the location, the almost incessant rain, the intense heat and the ignorant negro labor, he will get a faint idea of the difficulties that had to overcome in all branches of this installation (1912, p. 584).

Ao lado das características do território e do clima, "the ignorant negro labor" é considerada como um obstáculo para a concretização da usina. 0 julgamento do autor - um engenheiro, provavelmente - pode ser entendido como mecanismo para desresponsabilizar os engenheiros e a companhia das mortes ocorridas durante as obras. Atribuir a culpa à raça dos trabalhadores é uma forma de reelaboração de um discurso racista e recorrente de que negros, índios e povos aborígenes são preguiçosos, irracionais e negligentes. Reafirmando, dessa forma, um discurso imperialista de que os brancos são laboriosos, eficazes, racionais e, portanto, isentos de culpa nas fatalidades ocorridas na usina.

0 fragmento apresentado acima leva a crer que acidentes de trabalho eram relativamente comuns durante a construção do canal. Não obstante, não foi encontrado nenhum outro registro a respeito de acidentes no canal ou no restante da usina.

De acidentes ocorridos nas obras do canal ao traço da argamassa utilizada nas fundações da casa de força, as informações publicadas em artigos técnicos a respeito de Itatinga constituem fontes preciosas para a compreensão da própria usina. Da mesma forma, este material nos possibilita situar a relevância e o alcance da Usina de Itatinga no panorama mundial do início do século XX. Assim sendo, este artigo buscou descortinar, por meio do estudo de caso de Itatinga, fontes que podem contribuir para a compreensão das primeiras usinas construídas no Brasil. Seja como repertório para o projeto de usinas, seja como meio de difusão destes empreendimentos, os tratados e as revistas especializadas constituem fontes ricas e ainda pouco exploradas para a escrita da história das hidrelétricas brasileiras.

\footnotetext{
11 Dentre os artigos que tratam exclusivamente da Usina de Itatinga estão: BERENGER, José M. Usina Hidrelétrica de Itatinga. Revista G.E. São Paulo, n. 4, p. 29-31, jul., 1954; FREDERICK, P. A notable hydro-electric development in South America. General electric review, New York, vol XV, n 10, 1912; HYDROELECTRIC station of the Cia Docas de Santos. Electrical World. New York, v 59, n 11, 1912. WEINSHENCK, G. Breve Notícia sobre a instalação hydro-electrica do Itatinga. Revista Polytechnica. São Paulo, n 28, vol V, p.253-258, 1909. Nos seguintes artigos, Itatinga é tratada em meio a outras usinas: A Brazilian Hydroelectric plant utilizing a 2100-foot Head. The Engineering Record, Building Record and Sanitary Engineer. New York, vol 65, 1912; BILLINGS, A. W. K. Water power in Brazil. The engineering journal. Montreal, n 8, vol XIII, ago.,1930; BUSINES Notes. The Electrical Review. London, vol 71, 1912; L'ELECTRICITE au Bresil d'apres les rapports officiels. La Lumière électrique: revue universelle d'électricité. Paris, s.d.; MÜLLER, A. ; JOSSE, E. Wasserkraftanlage in Brasillien. Zeitschrift für das Gesamte Turbinenwesen. München, vol 9, 1912; PEREZ, E. E. From Latin America special correspondence. Mining and Engineering World. Chicago, vol 42, 1915; WANDERLEY, Luiz Os Exercícios práticos da cadeira de mecânica applicada às machinas. Revista Polytechnica. São Paulo, n 43, vol VII, p.236-261, 1913; WASSERMOTOREN, windmotoren, pumpen. E und M: Elektrotechnik und Maschinenbau. Vienna, vol 30,1912. Itatinga também é frequentemente mencionada em listagens das usinas hidrelétricas da América Latina publicadas em periódicos norte americanos e europeus.
} 


\section{Referências}

ADAMS, Alton D. Electric transmission of water power. New York: McGraw Publishing Company, 1906.

BAUM, F. G. The alternating current transformer. New York: McGraw Publishing Company, 1903.

BELL, Louis. Electric power transmission; a practical treatise for practical men. New York: Electrical world and engineer incorporated, 1901.

BERENGER, José M. Usina Hidrelétrica de Itatinga. Revista G.E. São Paulo, n. 4, p. 29-31, jul., 1954.

CLOQUET, Louis. Traité d'architecture, 5 vols. Paris et Liége: Libraire Polytechnique, Baudry et Cie. , 1898-1901.

FREDERICK, P. A notable hydro-electric development in South America. General electric review, New York, vol XV, n 10, 1912.

GESCHICHTE der TU Chemnitz. Disponível em <https://www.tu-chemnitz.de/tu/geschichte/ zeittafel.php> Acesso em 03 mar 2014.

HORNER, Joseph G. Henley's encyclopædia of practical engineering and allied trades. New York: The N.W. Henley Pub. Co., 1906.

HUTCHINSON, Rollin W. Long-distance electric power transmission. New York: D. Van Nostrand Company, 1907.

HYDROELECTRIC station of the Cia Docas de Santos. Electrical World. New York, v. 59, n. 11, 1912.

KOESTER, Frank. Hydroelectric developments and engineering. New York: D Van Nostrand Company, 1909.

MAZIVIERO, Maria Carolina. Memória e identidade urbana em Santos: usos e preservação de tipologias arquitetônicas da Avenida Conselheiro Nébias. 2008. Dissertação (mestrado). Faculdade de Arquitetura e Urbanismo/USP, São Paulo.

REYNAUD, Léonce. Traité d'architecture, 2 vols. Paris: Dunod, 1875-1878.

ROCHA, P. Mendes. Engenheiro Guilherme Benjamin Weinschenck. São Paulo, 1948.

ROSS, Genevieve. Colgate Powerhouse. Appeal democrat. 13 Set 1999. Disponível em <http:// www.appeal-democrat.com/published-monday-september/article_833c3b8e-9140-55dd-824eef49fe779013.html> Acesso 4 mar 2014.

SEGURADO, João E. S. Alvenaria e cantaria. Lisboa: Bertrand, s.d.

SEGURADO, João E. S. Trabalhos de Carpintaria Civil. Lisboa: Bertrand, s.d.

WEINSHENCK, G. Breve Notícia sobre a instalação hydro-electrica do Itatinga. Revista Polytechnica. São Paulo, n 28, vol V, p.253-258, 1909.

WEISCHENK, Guilerme B. Itatinga Cálculos, 5 vols. Santos, 1903-1908. 